\title{
Newborn Intramuscular Hemangioma Revealed by Forearm Compartment Syndrome: Difficult Diagnosis in Less Developing Country
}

\section{Zavier Zomalheto, Michel Fiogbe, Michée Assogba}

BP 2139 Abomey-Calavi, Abomey-Calavi, Benin.

Email: zozaher@yahoo.fr, cosherv12@yahoo.fr, amichee12@yahoo.fr

Received September $3^{\text {rd }}$, 2013; revised October $3^{\text {rd }}$, 2013; accepted October $10^{\text {th }}, 2013$

Copyright (c) 2013 Zavier Zomalheto et al. This is an open access article distributed under the Creative Commons Attribution License, which permits unrestricted use, distribution, and reproduction in any medium, provided the original work is properly cited.

\begin{abstract}
The forearm intramuscular hemangiomas are increasingly described in the literature. The most common variants are about old children and teenagers. We reported a case of a forearm intramuscular hemangioma at a newborn, revealed by a compartment syndrome, which diagnosis were hard in a developing country as ours.
\end{abstract}

Keywords: Hemangioma; Newborn; Compartment Syndrome; Benin

\section{Introduction}

The infantile intramuscular hemangioma is a benign vascular tumor present at $10 \%$ of the infants. It is up to the group of the vascular tumors in the classification of the International Society for the Study of Vascular Anomalies [1-4]. This cutaneous tumor can extend to adjacent tissues, in particular oral cavity or genitals, and may be associated with visceral hemangioma.

Its diagnosis is easy and characterized in its cutaneous common form by an explosive postnatal growth and secondarily a slow regression. In this order, the tumour appears as a red tuberous mass, subcutaneous mass or mixed shape in "poached egg". However, the diagnosis can become hard in the in particular subcutaneous uncommon forms, sometimes leading diagnostic wanderings [5].

We reported a newborn forearm hemangioma which diagnosis was difficult.

\section{Case Report}

The 19-month-old boy has presented since birth a soft tumefaction of right forearm which was slightly painful to the palpation. An obstetric trauma had been suspected at the birth but the imaging tests did not plead in favor.

The progressive increase of the tumefaction's proliferation and occurring angular deformity in irreducible flexion of the wrist and fingers motivated a pediatric consultation at the 5th month.

Examination showed preserved general health without underdevelopment. Neurological examination of the right upper limb revealed a compartment syndrome with painless puriform tumefaction of the forearm and retraction of the wrist and fingers flexion-holding which had swanneck duck appearance (Figure 1). A scanner of the forearm showed a tumefaction of the soft tissues of forearm with homogeneous areas seeming well limited without calcification neither tumor necrosis, nor bone injury (Figure 2).

A tumor of soft tissues was then suspected and a clinical monitoring put on the spot.

At 15 months, there was a stationary clinical status with a puriform tumefaction which longitudinal main axis were about 8 centimeters. X-ray of the forearm showed a tumefaction of soft tissues without adjacent bone injury. Facing up to this seemingly benign tumor with neurological complication and absence of Magnetic Resonance Imaging (MRI) unavailable in our country, an exploratory surgical procedure was decided after a multidisciplinary dialogue. The surgery was realized by a tumor areaoriented incision on the anterior face of the forearm. After aponeurotomy, there was no tumor mass, but a diffuse infiltration with induration of all the tendons and muscular masses of forearm anterior compartment (Figure 3). Biopsy samples were realized followed by suture in 2 plans of the surgical wound. Then a plaster above arm 


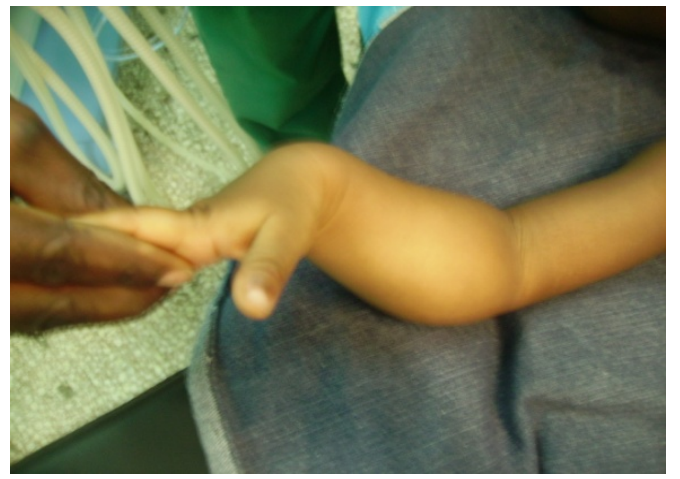

(a)

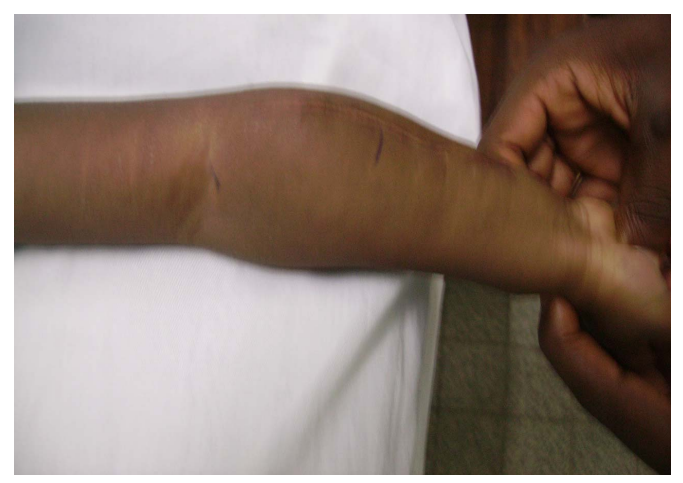

(b)

Figure 1. Retraction of the wrist flexion-holding which had swan-neck duck appearance before surgery (a) and after surgery (b).

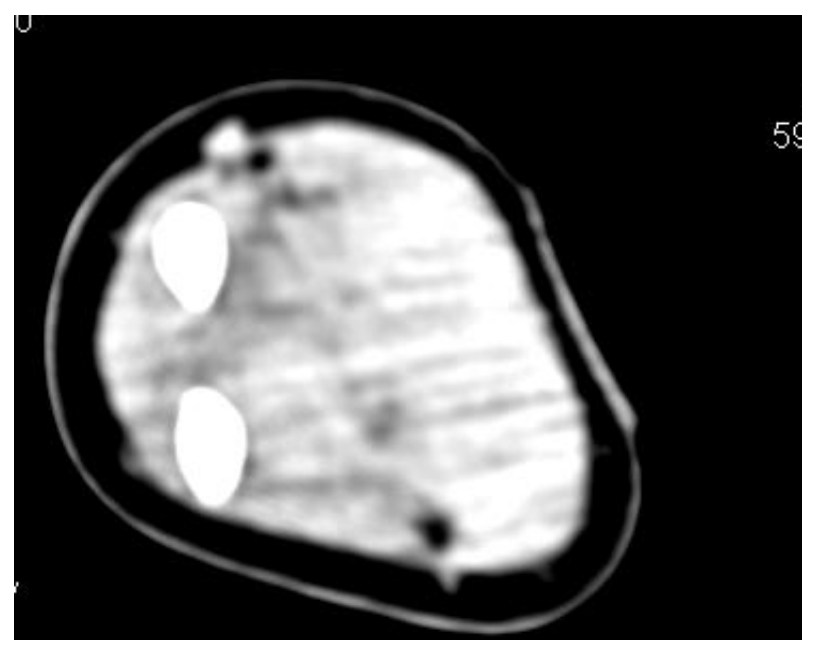

Figure 2. CT showing muscular hemangioma.

to palmer with the wrist hyper extension was applied during 14 days.

The histological study of the specimen taken intraoperatively revealed extensive fibrotic tissue containing striated muscle bundles with at heart, a diffuse vascular cell proliferation, making pathology reported to a benign hemangioma with atrophy of skeletal muscle.

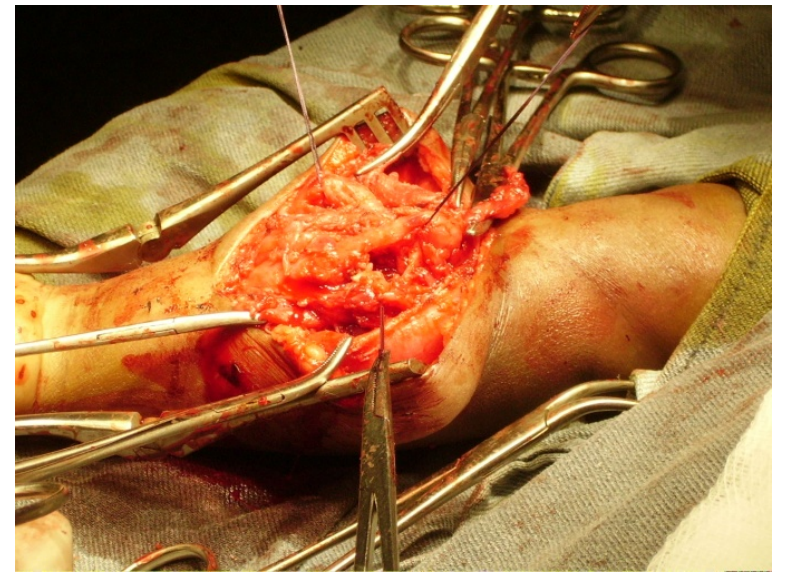

Figure 3. Infiltration of tissue lodge forearm.

In the evolutionary, at the 30th post-operative day, the forearm circumference about $4 \mathrm{~cm}$ above the elbow crease was $18 \mathrm{~cm}$ and after a cardiology consultation, the child was given Propranolol ( $25 \mathrm{mg} / \mathrm{m}^{2} /$ day). On the 12 th week, the forearm circumference was about $16 \mathrm{~cm}$ against $14 \mathrm{~cm}$ at the opposite limb. There were no more neurological disorders and the functionality of the limb was correct.

\section{Discussion}

Muscular hemangioma is not common. The infantile variant is not often present at the birth but develops in a few weeks of life. The preferred site is the "head and neck” area (80\%), mostly anterior cheek, forehead and pre-auricular area. Cutaneous tissues can be affected in $10 \%$ of the cases [6]. Impairment of the limbs as forearm in our case is rare.

Muscular hemangioma represents $0.8 \%$ of hemangioma, any merged localizations and 7 at $10 \%$ of the benign tumors of soft tissues. Pathogenesis is unclear.

Contrary to the present case, the tumor generally affects female preponderance. There is most often only one lesion but $20 \%$ of the patients have multiple lesions. Complications can occur, mostly depending on the size of the lesion; with sometimes very significant damages as at our boy whose tumor led angular deformity of the elbow and hand by damaging vascular-nervous pad. The shape with multiple lesions can rarely be life-threatening because of associated visceral injuries, in particular brain, liver and the digestive tract $[7,8]$. We didn't note any sign of visceral distress at our boy.

Muscular hemangioma diagnosis is clinical in the most cases. A biopsy is rarely necessary. This can arise when the lesion has an uncommon clinical presentation as at our boy at whom the hemangioma was diagnosed only after biopsy samples.

The most common clinical manifestation of intramus- 
cular hemangioma is a painless tumefaction with slow course. Complications are however possible: fistulization, hemorrhage, hematoma or thrombosis. Some complications are more specific of the forearm: neuropathy of ulnar or median nerve by tumor compression. The compartment syndrome observed in our patient led swan neck wrist and monkey hand. Recovery was total after a few months [9].

MRI is the most successful method of imagery for hemangiomas [10]. It demonstrates well-circumscribed and allows natural diagnosis; helped by various lying of signal for intramuscular hemangiomas and uninvolved adjacent muscles. On the T2-weighted images, MRI show net limits of intramuscular hemangioma and hyperintense signal contrary to images of muscle and fat subcutaneous tissues. The absence of MRI in our country led realization of exploratory surgery for establishing diagnosis.

Our case-report is very exceptional. In the literature review, we don't see similar cases. Forearm compartment or wolkmann like contracture of the forearm muscles have been described by Sunil [11] and Ragland and al [12] on the new born without large part of intramuscular hemangioma.

\section{Conclusion}

Infantile hemangioma diagnosis is clinically in most of the cases. Nevertheless, there are uncommon variants which can make misdiagnosis. The originality of this study comes from being the first case observed in our country and having engendered diagnostic wanderings. The second interest lies in the presence of the neurological complications revealed by compartment syndrome.

\section{REFERENCES}

[1] O. Enjolras, "Classification and Management of the Various Superficial Vascular Anomalies: Hemangiomas and Vascular Malformations," Journal of Dermatology, Vol. 24, 1997, pp. 701-710.

[2] O. Enjolras and J. B. Mulliken, "Vascular Tumors and
Vascular Malformations (New Issues) Chapter 12. Advance in dermatology,” Mosby-Year Book, Inc., 1998.

[3] M. Wassef and O. Enjolras, "Superficial Vascular Malformations: Classification et Histopathology," Annals of Pathology, Vol. 19, No. 3, 1999, pp. 253-264.

[4] E. O. Angioma, "La Revue du Praticien,” Vol. 53, 2003, pp. 899-905.

[5] A. Dompmartin, L.-M. Boon and D. Labbé, "Infantile Hemangiomas: Differential Diagnosis and Associated Anomalies," Annals of Pathology, Vol. 19, No. 3, 1999, pp. 253-264.

[6] S. Fraitag, "Vascular Tumors and Pseudo-Tumors. Infantile Haemangioma,” Annals of Pathnology, Vol. 31, 2011, pp. 253-259. http://dx.doi.org/10.1016/j.annpat.2011.04.010

[7] A. Stockman, F. Boralevi, A. Taieb and C. Leaute-Labreze, "Sacral Syndrome: Spinal Dysraphism, Anogenital, Cutaneous, Renal, and Urologic Anomalies Associated with an Angioma of Lumbosacral Localization,” Dermatology, Vol. 214, 2007, pp. 40-45. http://dx.doi.org/10.1159/000096911

[8] S. G. N. Goh and E. Calonje, "Cutaneous Vascular Tumours: An Update,” Histopathology, Vol. 52, 2008, pp. 661-673.

http://dx.doi.org/10.1111/j.1365-2559.2007.02924.X

[9] S. Fnini, A. Messoudi, Y. Benjeddi, Y. Elandaloussi, J. Hassoun, A. Garche, M. Ouarab and A. Largab, "Intramuscular Hemangioma of the Forearm: Seven Cases," Annales de Chirurgie Plastique Esthétique, Vol. 58, 2013, pp. 243-247. http://dx.doi.org/10.1016/j.anplas.2010.08.004

[10] C. Girard, M. Ignore, B. Guillot and D. Bessis, "Pelvis Syndrome,” Archives of Dermatology, Vol. 142, 2006, pp. 884-888. http://dx.doi.org/10.1001/archderm.142.7.884

[11] T. M. Sunil, "Intramuscular Hemangioma Complicated by a Volkmann's Like Contracture of the Forearm Muscles,” Indian Pediatrics, Vol. 41, No. 3, 2004, pp. 270 273.

[12] R. Ragland, D. Moukoko, M. Ezaki, P. R. Carter and J. Mills, "Forearm Compartment Syndrome in the Newborn: Report of 24 Cases,” Journal of Hand Surgery, Vol. 30, No. 5, 2005, pp. 997-1003. http://dx.doi.org/10.1016/j.jhsa.2005.06.003 